\title{
SYNTHETIC RATES OF MONOAMINE OXIDASE IN RAT LIVER AFTER CLORGYLINE OR DEPRENYL ADMINISTRATION
}

\author{
Toru EGASHIRA and *Kazuya KAMIJO \\ Department of Pharmacology, Medical College of Oita, Toi, \\ Hazama-cho, Oita 879-55, and \\ * Department of Pharmacology, School of Medicine, Showa University, \\ Hatanodai, Shinagawa-ku, Tokyo 142, Japan
}

Accepted March 14, 1979

Monoamine oxidase (MAO; monoamine; $\mathrm{O}_{2}$ oxidoreductase (deaminating); EC 1.4.3.4), which deaminates various aromatic amines, is mainly located in the mitochondria of mammalian tissues (1). This enzyme is used as a marker of mitochondria since it has been shown to be associated with mitochondrial outer membranes (2). There is recent evidence for the existence of two types of MAO in rat liver mitochondria $(3,4)$ : a type called "A: that is inhibited by clorgyline (5), and a type called " $\mathrm{B}$ " that is inhibited by deprenyl (6). Little is known about the origin or synthesis of mitochondrial MAO, although the rate of synthesis of MAO has been studied by measuring the rate of recovery of activity after administration of MAO inhibitors $(7,8)$. We examined the relation between the precursor pool and the restoration of MAO activity in liver microsomes and mitochondria after administration of the irreversible MAO inhibitors, clorgyline and deprenyl to rats by measuring the rates of recovery of type A and $\mathrm{B}$ MAO activities after treatment with inhibitors.

Male Wistar rats weighing $80-100 \mathrm{~g}$ were used. A dose of $20 \mathrm{mg} / \mathrm{kg}$ of clorgyline (a specific inhibitor of type A MAO) or deprenyl (a specific inhibitor of type B MAO) in $0.5 \mathrm{ml}$ saline was given to rats intraperitoneally. The rats were then anesthetized with $10 \mathrm{mg} / \mathrm{kg}$ of sodium pentobarbital and the livers quickly removed and homogenized with 10 volumes of $0.25 \mathrm{M}$ sucrose ( $\mathrm{pH} 7.2$ ). The mitochondrial and microsomal fractions were prepared by differential centrifugation as described by Schneider and Hogeboom (9). The mitochondria and microsomes were washed once by resuspension in $0.25 \mathrm{M}$ sucrose solution and used as the enzyme preparations. These operations were carried out at $4{ }^{\circ} \mathrm{C}$. The protein contents of the preparations were measured by the method of Lowry et al. (10) with bovine albumin used as the standard; preparations containing $10 \mathrm{mg} / \mathrm{ml}$ of protein were used for enzyme assay. MAO activity was estimated by radioisotopic assay with ${ }^{14} \mathrm{C}$-serotonin (substrate for type A MAO) and ${ }^{14} \mathrm{C}$ - $\beta$-phenylethylamine (substrate for type B MAO) as described previously (4).

The MAO activities in rat liver mitochondria and microsomes were measured after administration of $20 \mathrm{mg} / \mathrm{kg}$ of clorgyline or deprenyl with serotonin and $\beta$-phenylethylamine as substrates. As shown in Fig. 1 (A), with serotonin as substrate, the activity in mitochondria was $10 \%$ of the control activity $12 \mathrm{hr}$ after administration of clorgyline and then increased gradually, being $50 \%$ of the control value after 3 days, and close to the control value after 2 weeks. With $\beta$-phenylethylamine as substrate, the MAO activity was about $80 \%$ of the 

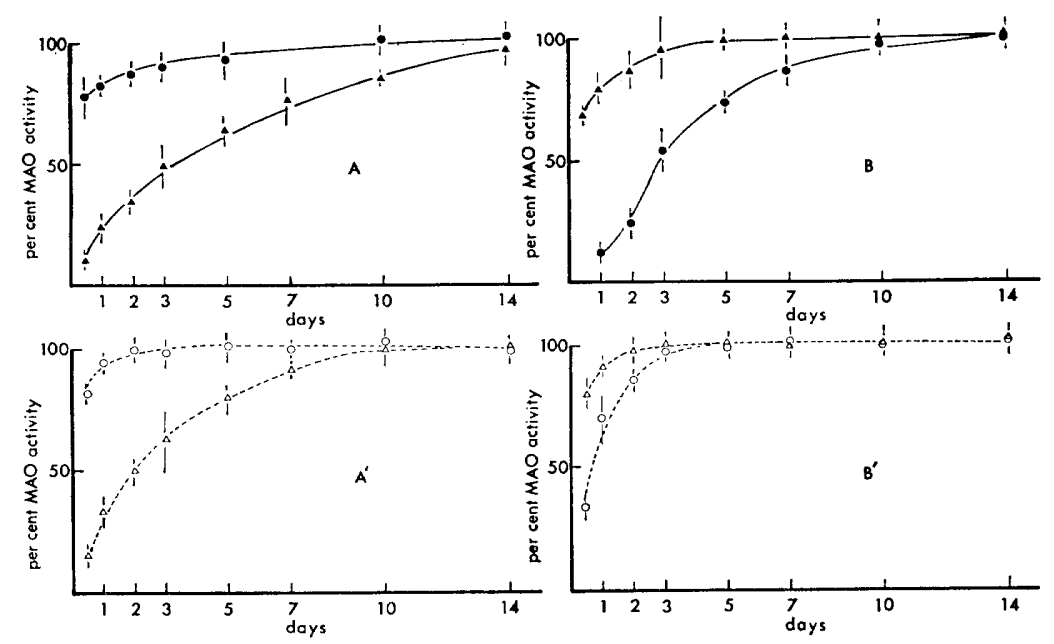

FIG. 1. Rate of recovery of MAO activity in rat liver following administration of clorgyline and deprenyl. Mitochondrial and microsomal fractions were prepared as described in the text from animals given i.p. $20 \mathrm{mg} / \mathrm{kg}$ of clorgyline ( $\mathrm{A}$ and $\mathrm{A}^{\prime}$ ) or deprenyl (B and $\left.\mathrm{B}^{\prime}\right)$. MAO activity was determined with ${ }^{14} \mathrm{C}$-serotonin $(\Delta-\Delta, \triangle \cdots \Delta)$ and ${ }^{14} \mathrm{C}$ - $\beta$-phenylethylamine $(\mathbf{O}, \bigcirc-\bigcirc)$ as substrates. Results obtained with mitochondria (A and B) and microsomes $\left(A^{\prime}\right.$ and $\left.B^{\prime}\right)$ are shown. Values are means for triplicate experiments. The mean - S.E. control values for MAO activity in mitochondria were $0.55 \pm 0.059$ nmoles $/ \mathrm{min} / \mathrm{mg}$ protein for serotonin, $0.36-t-0.027 \mathrm{nmoles} / \mathrm{min} / \mathrm{mg}$ protein for $\beta$-phenylethylamine and $0.120 .0095 \mathrm{nmoles} / \mathrm{min} / \mathrm{mg}$ protein for serotonin and $0.08-0.0073 \mathrm{nmoles} / \mathrm{min} / \mathrm{mg}$ protein for $\beta$-phenylethylamine in microsomes.

control value $12 \mathrm{hr}$ after administration of clorgyline and then the activity increased rapidly, with a complete restoration within 10 days.

The curves for recovery of activity in microsomes with serotonin and $\beta$-phenylethylamine as substrates (Fig. 1, $\mathrm{A}^{\prime}$ ), were quite similar, and in both cases, the rates of recovery of activity were faster than those in the mitochondrial preparation. The recoveries of MAO activity in rat liver mitochondria and microsomes after administration of $20 \mathrm{mg} / \mathrm{kg}$ deprenyl were similar to those after treatment with clorgyline (Fig. 1, B and B'). These findings suggest the existence of a precursor pool for synthesis of microsomal and mitochondrial MAO. Although the origin of mitochondrial MAO is unknown, some workers consider that such may be synthesized in the microsomes.

On the basis of Johnston's proposal of the existence of type A and B MAO (5), Fig. 1 shows the recovery of type A MAO (left) and type B MAO (right) in mitochondria and microsomes of rat liver. From these results, turnover rates of these MAO's were calculated by the method of Goridis and Neff (11); that is, from a plot of the percent inhibition of MAO activity vs. the time after administration of clorgyline or deprenyl on a semilogarithmic scale (Fig. 2). In this way the half-life of type A mitochondrial and of microsomal MAO was estimated to be 3.49 and 1.95 days, respectively, and the half-life of type B mitochondrial and microsomal MAO to be 2.64 and 0.61 days, respectively. These results suggest that 


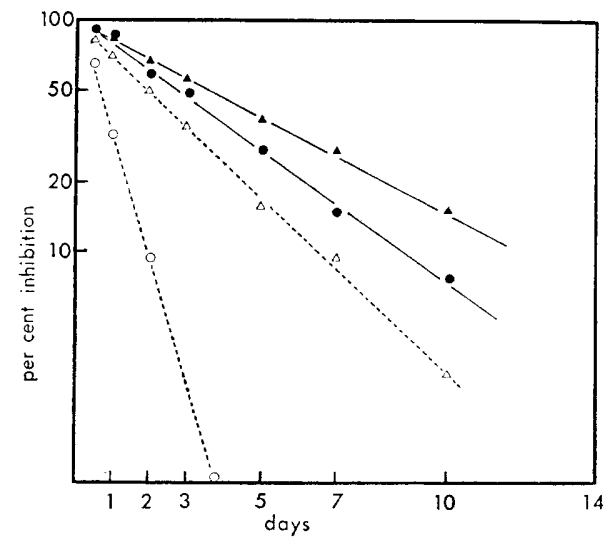

Fig. 2. Recoveries of type A and B MAO activities in rat liver mitochondria and microsomes after treatment with clorgyline and deprenyl. Mitochondria and microsomes were used as enzyme preparations. Type A MAO: mitochondria ( $\Delta$ ), microsomes $(\wedge \cdots)$, type B MAO: mitochondria $(-\infty)$, microsomes $(0)$

recovery of type A MAO activity is slower than that of type B MAO. Our values are similar to those estimated using pargyline (8), a compound which appeares to bind covalently and irreversibly with the catalytic site of MAO (12). The turnover rates of individual mitochondrial proteins vary considerably; for example, these rates of proteins in the outer membrane of liver mitochondria are significantly higher than those of proteins in the inner membrane (13). Moreover, estimated values of the turnover rate are method dependent. Factors, such as age may also affect the rate of recovery of MAO activity.

Our results indicate that after injection of inhibitors, MAO activity in the liver gradually returns to normal. Thus activity in the brain and heart may also be expected to recover after treatment with inhibitors. We are now using inhibitors of protein synthesis, in further studies on the physiology of MAO in mitochondria and microsomes.

\section{REFERENCES}

1) Youdim, M.B.H. and Sourkes, T.L: Properties of purified soluble monoamine oxidase. Canad. J. Biochem. 44, 1397-1400 (1966)

2) Greenawalt, J.W.: Localization of monoamine oxidase in rat liver mitochondria. $A d v$. Biochem. Psychopharmacol. 5, 207-226 (1972)

3) EKSTEDT, B.: Substrate specificity of the different forms of monoamine oxidase in rat liver mitochondria. Biochem. Pharmacol. 25, 1133-1138 (1976)

4) Egashitra, T., Ekstedt, B. and Oreland, L.: Inhibition by clorgyline and deprenyl of the different forms of monoamine oxidase in rat liver mitochondria. Biochem. Pharmacol. 25, 2583-2586 (1976)

5) Johnston, J.P.: Some observations upon a new inhibitor of monoamine oxidase in brain tissue. Biochem. Pharmacol. 17, 1285-1297 (1968)

6) KNOLL, J. AND MagYar, K.: Some puzzling pharmacological effects of monoamine oxidase inhibitors. Adv. Biochem. Psychopharmacol. 5, 393-408 (1972)

7) Erwin, V.G. and Simon, R.J.: Occurrence of newly synthesized monoamine oxidase in subcellular fractions of the rat liver. J. Pharm. Sci. 58, 1033-1035 (1969)

8) Erwin, V.G. and Deitrich, R.A.: The labeling in vivo of monoamine oxidase by ${ }^{14} \mathrm{C}$ - 
pargyline; a tool for studying the synthesis of the enzyme. Mol. Pharmacol. 7, 219-228 (1971)

9) Schneider, W.C. And Hogeboom, G.H.: Intracellular distribution of enzyme. V. Further studies on the distribution of cytochrome $\mathrm{c}$ in rat liver homogenates. J. biol. Chem. 183, 123-128 (1950)

10) Lowry, O.H., Rosebrough, N.J., Farr, A.L. and Randall, R.J.: Protein measurement with the Folin phenol reagent. J. biol. Chem. 193, 265-275 (1951)

11) Goridis, C. AND NefF, N.H.: Monoamine oxidase: An approximation of turnover rates. J. Neurochem. 18, 1673-1682 (1971)

12) Hellerman, L. and Erwin, V.G.: Mitochondrial monoamine oxidase II. Action of various inhibitors for the bovine kidney enzyme catalytic mechanism. J. biol. Chem. 243, 5234-5243 (1968)

13) Druyan, R., DeBernard, B. and Rabinowitz, M.: Turnover of cytochromes labeled with $\delta$-aminolevulinic acid-. ${ }^{3} \mathrm{H}$ in rat liver. J. biol. Chem. 244, 5874-5878 (1969)

\title{
ALTERATION OF HEPATIC ADENYLATE CYCLASE ACTIVITY FOLLOWING CONTINUOUS ETHANOL ADMINISTRATION
}

\author{
Kinya KURIYAMA, Makoto MURAMATSU and Meiko NAGANO* \\ Department of Pharmacology, Kyoto Prefectural University of Medicine, \\ Kamikyo-ku, Kyoto 602, Japan
}

Accepted April 2, 1979

It has been reported that continuous oral administration of ethanol (EtOH) increases the content of adenosine cyclic 3',5'-monophosphate (cyclic AMP), and the activities of adenylate cyclase (A.C) $(1,2)$ and cyclic AMP-dependent protein kinase (3) in the mouse cerebral cortex. It was also found that the stimulatory effect of added biogenic amines on the formation of cyclic AMP in cerebral cortical slices from these ethanol-treated animals is reduced significantly (4). On the other hand, Miki et al. (5) found that inhalation of ethanol inhibits the hepatic guanylate cyclase activity measured in the presence of $\mathrm{NaN}_{3}$. Although it has been shown that acute EtOH load by gastric administration increases the cyclic AMP content in the rat liver (6) and in vitro addition of EtOH increases hepatic A.C activity of the rat (7), little information is available concerning the effect of $\mathrm{EtOH}$ on hepatic A.C activity in vivo. In this paper we describe the effect of EtOH administration in vivo on hepatic adenylate cyclase activity measured both in the presence or absence of various hormones.

Male mice (Std : ddY) weighing 20-30 g were used in all experiments. For continuous administrations of EtOH, the inhalation method of Goldstein (8) and liquid diet method of De Carli and Lieber (9) were used, respectively. In the inhalation experiments, the air containing $30-42 \mathrm{mg}$ of $\mathrm{EtOH} / 1$ flowed through the mixing flask and chamber $(51 \times 30 \times 30 \mathrm{~cm})$ at the rate of $21 / \mathrm{min}$. To maintain a high blood level of EtOH, pyrazole

* Present Address: Division of Pharmacy, The University Hospital, Kyoto Prefectural University of Medicine, Kyoto 602, Japan 